\title{
Dust as a Potential Tracer for the Flow over Different Topographical Shapes Employing MODIS-Terra Observations
}

\author{
Joseph Barkan, Pinhas Alpert \\ Dept. Geophysics, School of Geosciences, Tel Aviv University, Tel Aviv, Israel \\ Email: yossib@post.tau.ac.il,pinhas@post.tau.ac.il
}

How to cite this paper: Barkan, J. and Alpert, P. (2018) Dust as a Potential Tracer for the Flow over Different Topographical Shapes Employing MODIS-Terra Observations. International Journal of Geosciences, 9, 428-434.

https://doi.org/10.4236/ijg.2018.97027

Received: May 12, 2018

Accepted: July 24, 2018

Published: July 27, 2018

Copyright (c) 2018 by authors and Scientific Research Publishing Inc. This work is licensed under the Creative Commons Attribution International License (CC BY 4.0).

http://creativecommons.org/licenses/by/4.0/

\begin{abstract}
The hypothesis, that the magnitude of the Froude number can represent the flow type around an obstacle was examined at several different topographical shapes in dust-laden environments. It was found that in most cases this hypothesis was true. Average of 16 May months AOT data extracted from the MODIS Terra satellite has shown that in case of Froude number less than one, the AOT isolines tend to follow the topographical contours of the mountain peak (the obstacle) along with a minimum AOT near the peak.
\end{abstract}

\section{Keywords}

Froude Number, Dust, MODIS, Topographical Obstacles

\section{Introduction}

This paper is an extension of [1] Alpert and Barkan (2015) which investigated the flow types, in this case employing TOMS dust as a tracer, around and above topographical obstacles. Here, the focus is not just on the flow around an ear-circular shaped obstacle, i.e., the Gebel Mara, Sudan, N. Africa, but rather around different topographical shapes.

Here, the Terra MODIS data for all May months, during 2000-2015, 16 years altogether, were employed. Hereafter, the monthly average, not the daily data was used, in order to reduce the noise. The scientific background was described in the previous paper.

\section{The Dust Data}

The dust data was obtained from the MODIS instrument, mounted on the TERRA satellite through the Giovanni-Web interface that allows users to analyze 
NASA's gridded data from various satellite observations.

MODIS (Moderate Resolution Imaging Spectroradiometer) is a key instrument aboard the Terra satellite. Terra's orbit around the Earth is timed so that it passes from north to south across the equator in the morning $(\sim 10: 30 \mathrm{~h})$. The MODIS, aboard the Terra and Aqua satellites, observes the Earth's entire surface every 1 to 2 days, crossing over the equator at 10:30 and 13:30 local time (LT) during the day and at 22:30 and 01:30 LT at night, respectively. The MODIS acquires data in 20 visible and shortwave infrared spectral channels and 16 thermal infrared channels. Among these channels, the 8.6 (Band 29), 11 (Band 31), and $12 \mu \mathrm{m}$ (Band 32) are widely used for dust detection. The original resolution of the Level-2 MODIS data was $10 \times 10 \mathrm{~km}$. While in Level-3, the data was changed into a regular grid with a resolution of $1^{\circ} \times 1^{\circ}$ [2] (Ruiz-Arias et al., 2013). Recently, a new algorithm was developed for MODIS, which provides aerosol optical depth (AOD) at $1 \mathrm{~km}$ resolution [3] (Chudnovsky et al., 2013).

[1] Alpert and Barkan (2015) employed the TOMS instrument which can supply data from desert environment. However there was some doubt if the MODIS can retrieve data above such a terrain [4] (Kaufman et al., 2000). However, recently several updated algorithms were developed which enable the MODIS to operate efficiently even above high-albedo surfaces like desert, e.g., [5] Liu et al. (2013), [6] Carboni et al. (2012), [7] Bilal et al. (2013).

\section{Methodology of the Data Processing}

For the mountain peaks and of the surrounding area topographical contours (in black) along with May AOT average (16 May months) isolines (in red) and the average wind vectors at the mean height of the peak, were plotted in Figure 1. The height chosen for the wind vectors was $850 \mathrm{hPa}$ being the nearest standard pressure-level, at the mid-height between the background heights and the mountain peaks.

The AOT values were taken from the Giovanni online visualization and analysis website for the peaks and the upwind site of the surrounding area. The temperature and wind data were obtained from the NCEP/NCAR reanalysis with 2.5 $\times 2.5$ deg. interval.

Table 1 summarizes the features of the chosen obstacles.

The airflow around these topographical shapes was investigated with the aid of remotely-sensed MODIS dust. The study was performed for 16 months of May during 2000-2015. May was chosen because it was found to be a dust-rich month.

\section{The May-Average Froude Number Variation}

As shown in our preceding study [1] (Alpert and Barkan, 2015) when the Froude number is less than 1, the fluid will tend to flow around the obstacle, while with Froude number exceeding 1 the fluid tends to flow above the obstacle. In Table 2 the Froude number values are shown by years and for the various obstacles. 


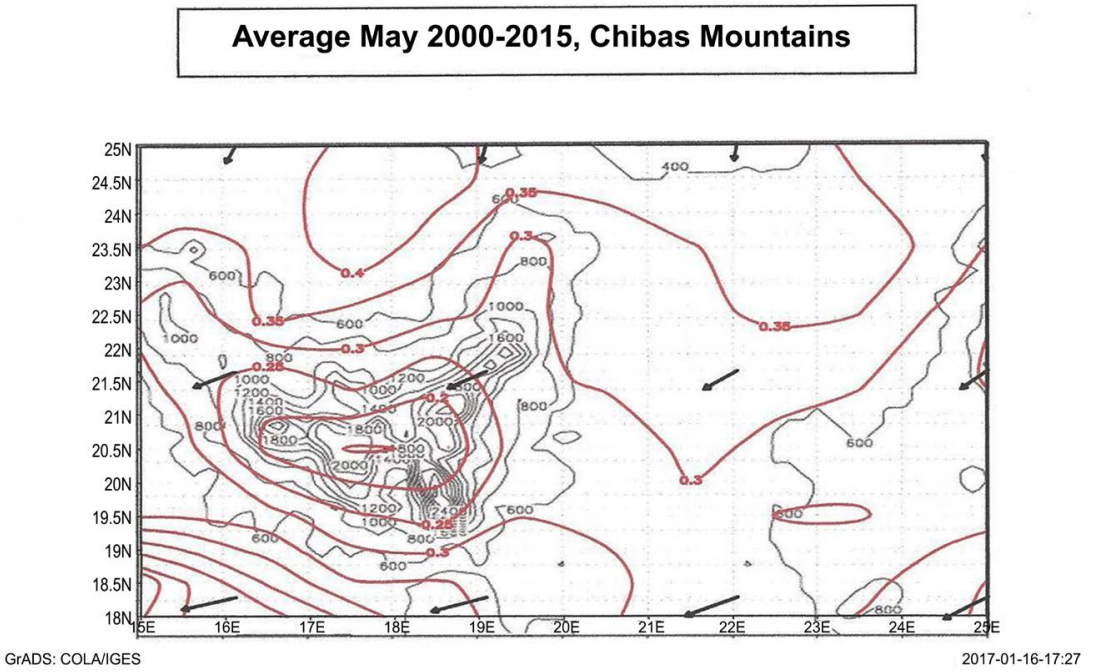

(a)

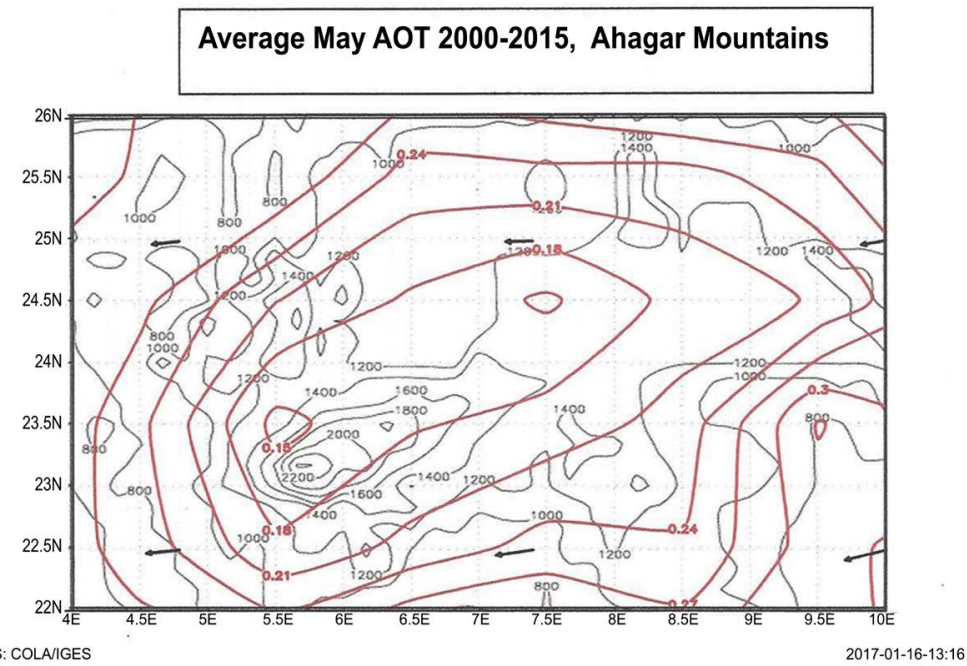

(b)

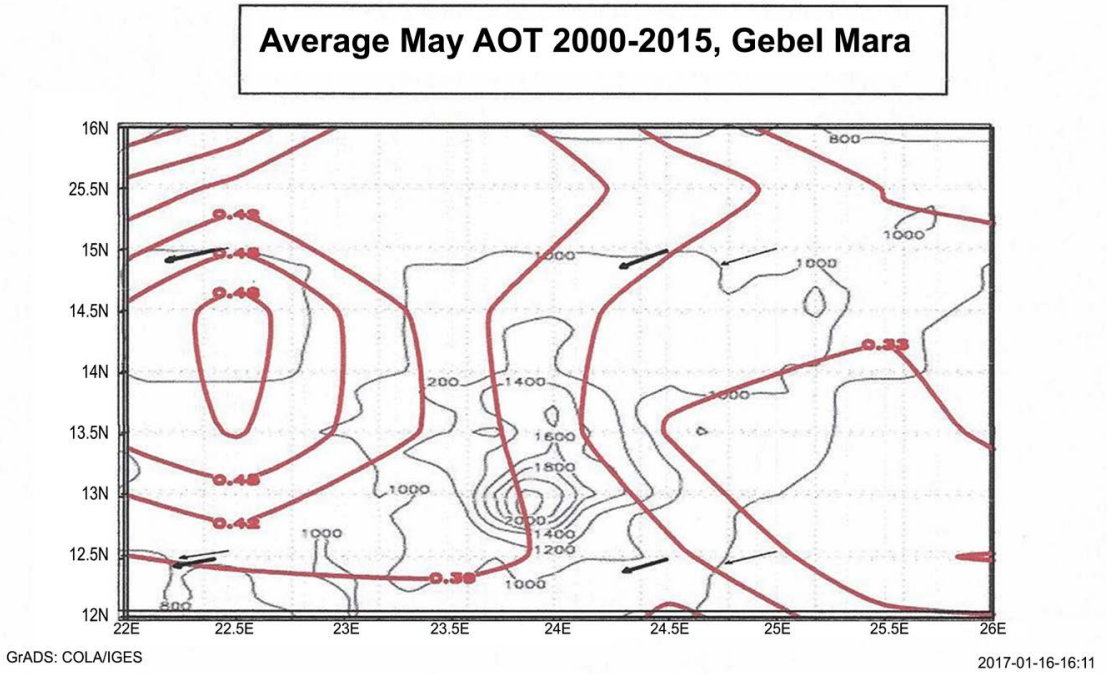

(c) 


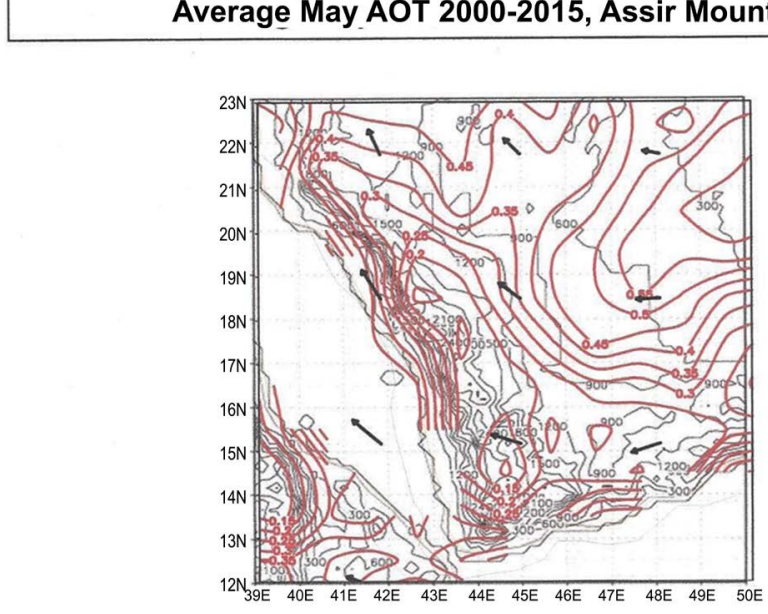

(d)

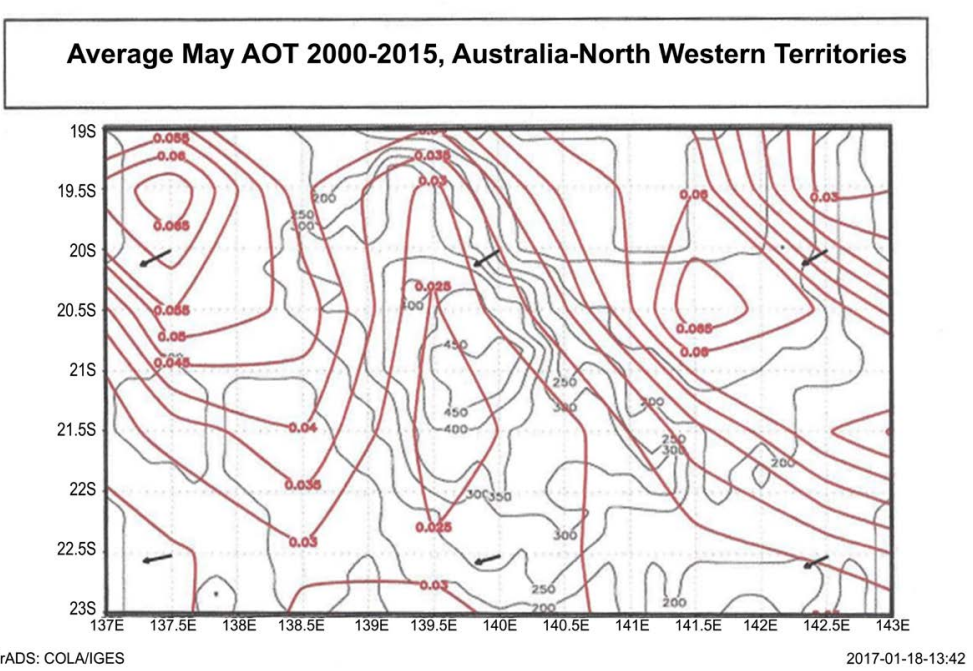

(e)

Figure 1. The distribution of the AOD and the topography around the following topographical obstacles: (a) Chibas Mountains (AOD interval of 0.05, topography interval 200 m); (b) Ahagar Mountains (0.03 \& 200 m); (c) Gebel Mara (0.03 \& 200); (d) Assir Mountains (0.05 \& 300); (e) Australia North-West Territories (0.005 \& 50).

Table 1. The 5 chosen topographical shapes including LON, LAT, Height (m) and shape, are listed.

\begin{tabular}{cccccc}
\hline & Ahagar Mtn. & Chibas Mtn. & Assir Mtn. & Gebel Mara & N.W. Australia \\
\hline Longitude & $4 \mathrm{E}-10 \mathrm{E}$ & $15 \mathrm{E}-25 \mathrm{E}$ & $39 \mathrm{E}-50 \mathrm{E}$ & $22 \mathrm{E}-26 \mathrm{E}$ & $137 \mathrm{E}-143 \mathrm{E}$ \\
Latitude & $22 \mathrm{~N}-26 \mathrm{~N}$ & $18 \mathrm{~N}-25 \mathrm{~N}$ & $12 \mathrm{~N}-23 \mathrm{~N}$ & $12 \mathrm{~N}-16 \mathrm{~N}$ & $23 \mathrm{~S}-19 \mathrm{~S}$ \\
Height $(\mathrm{m})$ & 2200 & 2400 & 2400 & 2000 & 450 \\
Shape & Elliptic & Triangular & Elongated & Circle & Circle \\
\hline
\end{tabular}

One can see that in the Chibas and Ahagar mountains the Froude number is less than one all along the 16 years. In the case of the Assir and Gebel Mara 
Table 2. Average Froude number per year for the months of May during 2000-2015.

\begin{tabular}{|c|c|c|c|c|c|}
\hline Year & Chibas & Ahagar & Mara & Assir & Australia Mt. \\
\hline 2000 & 0.179708 & 0.336952 & 2.205478 & 0.810443 & 3.154588 \\
\hline 2001 & 0.181315 & 0.1457 & 0.490522 & 0.473069 & 2.806407 \\
\hline 2002 & 0.176421 & 0.378045 & 0.987843 & 1.037783 & 1.052402 \\
\hline 2003 & 0.176487 & 0.14182 & 1.03569 & 0.534522 & 4.942527 \\
\hline 2004 & 0.179702 & 0.096269 & 1.04364 & 0.927822 & 1.144285 \\
\hline 2005 & 0.186474 & 0.199793 & 0.984368 & 0.981555 & 2.45153 \\
\hline 2006 & 0.179713 & 0.19255 & 0.738897 & 0.75691 & 2.108293 \\
\hline 2007 & 0.177944 & 0.714955 & 2.048195 & 0.414039 & 2.794747 \\
\hline 2008 & 0.17968 & 0.096257 & 0.985197 & 0.727074 & 1.237179 \\
\hline 2009 & 0.176432 & 0.70888 & 0.863813 & 0.537292 & 1.482758 \\
\hline 2010 & 0.179669 & 0.481255 & 0.518288 & 0.929021 & 1.748177 \\
\hline 2011 & 0.17897 & 0.383507 & 1.214286 & 0.811844 & 1.403203 \\
\hline 2012 & 0.179634 & 0.433047 & 1.386818 & 0.3286 & 0.858214 \\
\hline 2013 & 0.181292 & 0.485603 & 0.692231 & 0.694666 & 2.108293 \\
\hline 2014 & 0.178013 & 0.47682 & 0.423361 & 0.579889 & 1.256505 \\
\hline 2015 & 0.181298 & 0.388495 & 0.737653 & 0.472251 & 3.832301 \\
\hline mean & 0.179515 & 0.354623 & 0.994415 & 0.651233 & 1.97043 \\
\hline
\end{tabular}

mountains (Gebel meaning Mountain in Arabic) the Froude number is above or near one, especially in Gebel Mara, in which 6 out of the 16 years Fr $>1$. The Australia Mt., however, is entirely different. In all the 16 years Fr $>1$ and in some years, e.g. 2000, 2003 and 2015, it even exceeds 3.

In the case of the Australia Mt., the explanation is straightforward. This obstacle is relatively low $(\sim 450 \mathrm{~m})$ and even in stable atmospheric conditions with a reasonably windy environment, the dust may pass over the obstacle.

In the other two cases (Assir Mts. and Gebel Mara) we can offer a possible explanation: these two sites are located more to the south then the others-around $12-16 \mathrm{~N}$ (the Assir mountains are reach the $23 \mathrm{~N}$ parallel but the northern part is much lower). Due to their more southern location they are in the activity zone of the ITCZ twice a year, at its move to the north and its retreat to the south. This activity causes unstable atmospheric conditions and strong upward flow which drives the dust or other aerosols above the obstacles.

In summary, the 16-y mean Froude number was found less than one in all the investigated peaks, except to the Australia Mts., although in the Gebel Mara and the Assir Mts. The Fr number is closer to one than in the Chibas and Ahagar mountains.

Table 3 shows the AOT on the peak and at the upstream foot of the obstacle and the difference between them. Australia Mts. are not shown due to its different topography from the other obstacles. 
Table 3. The mean AOT value on and around the peaks.

\begin{tabular}{cccc}
\hline & On peak & At foot of mountain-upstream & Difference \\
\hline Chibas mountains & 0.2 & 0.3 & -0.1 \\
Ahagar Mountains & 0.15 & 0.24 & -0.09 \\
Gebel Mara & 0.37 & 0.5 & -0.13 \\
Assir mountains & 0.1 & 0.4 & -0.3 \\
\hline
\end{tabular}

\section{Discussion}

1) In the Chibas Mountains (Figure 1(a)) the AOT behaves exactly according to the theory. Though the topography is complicated, the AOT isolines follow in good proximity the height contours. The lowest values are next to the highest peak though somewhat to the northwest, presumable due to the Coriolis force.

2) In the Ahagar Mountains (Figure 1(b)) with elliptical topography, the AOT isolines, like in the previous case, follow nicely the height contours. The minimum AOT is situated near the highest peak somewhat to the northwest.

3) Gebel Mara's (Figure 1(c)) AOT distribution is exceptional. While in our previous study [1] (Alpert and Barkan, 2015) based on data from TOMS, the AI isolines followed almost perfectly the circular shape of the peak, here with the MODIS-TERRA data, the result is quite different. The minimum AOT is far from the peak and to the east. We have no satisfactory explanation to this particular result and it needs further research.

4) The Assir Mountains (Figure 1(d)) is an elongated ridge with two peaks, one at the south and the other at the middle of the ridge. The AOT isolines follow approximately the topography as in the other cases. A minimum AOT situated near of each peak but somewhat to the north.

5) The topography of this Australian peak (Figure 1(e)) is roughly round. The AOT isolines follow approximately the topography. In spite of the large froude number (1.97 average Froude number, Table 2), meaning that the bulk of the aerosols are passing above the peak, the minimum AOT is almost on the peak, a discrepancy which needs further research.

\section{Conclusions}

The assumption, based on the Froude number, that the behavior of the flow can be used as an open air hydrodynamic and thermodynamic laboratory, was reaffirmed approximately for different topographical features.

Several peaks with different topographies were examined, by means of averaged AOT data of 16 May months, from the MODIS (Moderate Resolution Imaging Spectroradiometer) on board, the TERRA satellite.

At all the peaks, excluding Australia, the average Froude number was less than one and accordingly the AOT isolines approximately followed the topographical contours of the peaks and the minimum AOT was found near the peak. Only two cases were exceptional: the AOT at the Australian peak behaved like the 
other peaks despite that its average Froude number was higher than one. On the other hand, the AOT's behavior at Gebel Mara was exceptional, i.e., the AOT isolines did not follow the topography and the minimum AOT was far from the peak. These outstanding features need further research.

\section{References}

[1] Alpert, P. and Barkan, J. (2015) Dust as a Potential Tracer for the Flow over Topography. International Journal of Geosciences, 6, 42-50. https://doi.org/10.4236/ijg.2015.61003

[2] Ruiz-Arias, J.A., Dudhia, J., Gueymard, C.A. and Pozo-Vázquez, D. (2013) Assessment of the Level-3 MODIS Daily Aerosol Optical Depth in the Context of Surface Solar Radiation and Numerical Weather Modeling. Atmospheric Chemistry and Physics, 13, 675-692. https://doi.org/10.5194/acp-13-675-2013

[3] Chudnovsky, A., Kostinski, Lyapustin, A. and Koutrakis, P. (2013) Spatial Scales of Pollution from Variable Resolution Satellite Imaging. Environmental Pollution, 172, 131-138. https://doi.org/10.1016/j.envpol.2012.08.016

[4] Kaufman, Y.J., Karnieli, A. and Tanré, D. (2000) Detection of Dust over Deserts Using Satellite Data in the Solar Wavelengths. IEEE Transactions on Geoscience and Remote Sensing, 38, 525-531. https://doi.org/10.1109/36.823947

[5] Liu, Y., Liu, R.G. and Cheng, X. (2013) Dust Detection over Desert Surfaces with Thermal Infrared Bands Using Dynamic Reference Brightness Temperature Differences. Journal of Geophysical Research: Atmospheres, 118, 8566-8584. https://doi.org/10.1002/jgrd.50647

[6] Carboni, E., Thomas, G.E., Sayer, A.M., Siddans, R., Poulsen, C.A., Grainger, R.G., Ahn, C., Antoine, D., Bevan, S., Braak, R., Brindley, H., DeSouza-Machado, S., Deuzé, J.L., Diner, D., Ducos, F., Grey, W., Hsu, C., Kalashnikova, O.V., Kahn, R., North, P.R.J., Salustro, C., Smith, A., Tanré, D., Torres, O. and Veihelmann, B. (2012) Intercomparison of Desert Dust Optical Depth from Satellite Measurments. Atmospheric Measurement Techniques, 5, 1973-2002.

[7] Bilal, M., Nichol, J.E., Bleiweiss, M.P. and Duboias, D. (2013) A Simplified High Resolution MODIS Aerosol Retrieval Algorithm (SARA) for Use over Mixed Surfaces. Remote Sensing of Environment, 136, 135-145.

https://doi.org/10.1016/j.rse.2013.04.014 